Most of the 16 societies represented in Florence, including the DPG and the IOP, indicated that they would recommend the proportional arrangement to members (the proposed starting date is January 1995, effectively the earliest). However, in order to develop precise financial estimates it is necessary to consider 1994 as a reference year. Following a membership survey this summer, national societies will be invoiced a total of 433 kSFR for 1994 under today's scaled scheme, and $570 \mathrm{kSFR}$ for the proportional arrangement assuming the current unit fee of SFR 14.50, with 16000 full members receiving News. Most societies who do not presently purchase News in bulk will therefore see their contributions increase. For some this will be difficult, especially during the economic transition in east and central Europe and in the aftermath of the recent round of currency devaluations elsewhere.

The Presidents felt, however, that their members would agree to redefining the relationship with EPS wherever possible, because the changes provide a sound basis for the Divisions and for future activities (not forgetting less visible aspects where the EPS acts, for instance, as a legal umbrella and a focal point for contacts with other organizations). Norbert Kroó, the President, indicated that the Society will also be able to focus on providing tangible benefits to all physicists

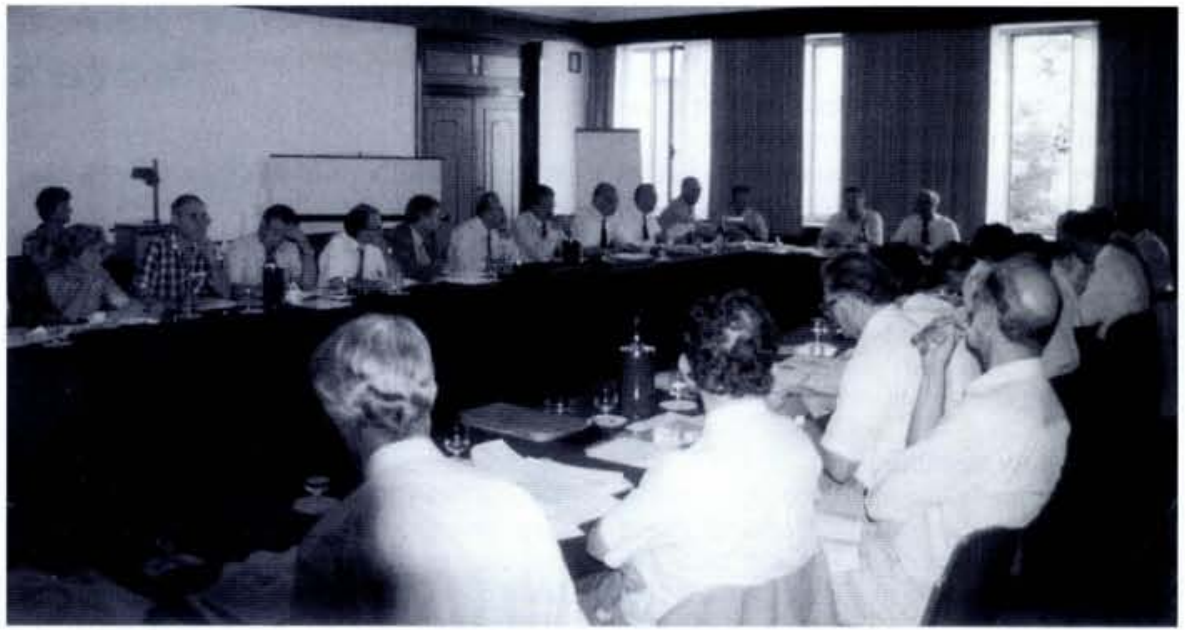

The Presidents of national societies meeting with the EPS Executive Committee in Florence on 13 September.

throughout Europe. The challenge here is to develop and support activities across an even broader front than up to now, in addition to handling essentially professional needs. Current forecasts indicate that with the help of contributions from individual members it should be possible to continue to set aside some funds for specific new activities even in the early stages of the proportional arrange- ment. There are understandably many details to be worked out, and the switch-over will need to be handled carefully. It was therefore very encouraging to hear at the meeting that the IOP and DPG were prepared to donate a total of 45 kSFR in 1994 for specific activities, so that the momentum of recent years can be maintained. Meanwhile, the constitutional aspects are being worked out.

\title{
GENERAL MEETING
}

\section{Emphasize New Opportunities}

"EPS is in good shape. The Divisions are organizing successful meetings, Europhysics News is functioning correctly, Europhysics Letters is a good venture, the Action Committees are enthusiastic, the Society has successfully balanced its budget in recent years and has, in general, fulfilled its task to bridge east and west. But much effort is needed to find extra resources for new activities in today's difficult economic climate". In these few words, the President, Norbert Kroó, summed up the status of EPS at the General Meeting of the ordinary members during EPS-9 in Florence.

But where to go from here? The President feels the Society must be opened up to new fields such as education. Hence the importance of the new Interdivisional Group for Physics Education and the student mobility scheme launched this month. More "professional services" should be offered, notably to international bodies such as the European Community, the problem at present being that things are not "organized appropriately." While there may be too many conferences, they nevertheless need to be enhanced as they are an essential part of scientific activity. There was some disappointment that more young people could not attend the General Conference. One remedy is to find funds to support participation at conferences - especially Divisional events - and to encourage young physicists to take part in Division activities, the most important element of the Society's life. One possibility would be to promote job opportunities.

There should also be a drive to find new members among more senior colleagues as the number of individual members (IOM's) has stayed fairly constant for the last decade or so. One must clearly activate national society members to join EPS by enhancing the rôle of the IOM's who are essentially people who want to do something for Europe as a whole. The Society has up to now focussed on professional activities and defined its boundary conditions accordingly: this should change to stimulate renewed interest. This is not to say that the Society has little to offer for there is a long list of activities. EPS also supports physicists indirectly by representing the community at the European level.

Hans Beck, who took over this year from Phillipe Choquard as Treasurer, reported that a surplus was still planned for 1993, bringing the accumulated deficit to just under 10 kSFR. A balanced budget has been prepared for 1994 prior to the meeting with the Presidents that left little for starting new activities. This obviously does not mean that the Society has no specific activities. It is simply that they are mostly funded from the general budget to ensure flexibility

\section{New Activities Highlighted}

Four major new activities were described, starting with André Landesman's review of the work of the East-West Coordination Committee. Most of the points he raised have been reported on elsewhere and foremost among the new elements was the disappointing news that the association set up in Luxembourg to support basic research in the former Soviet Union had got off to an unfortunate start. However, there have been developments and the situation is now much more promising. Hendrik Ferdinande gave an account of the status of the student mobility scheme which starts this month with 134 institutions and 107 students being involved in transfers in the first year - a remarkable achievement. It is clear that the scheme is in line with current European Community thinking on how mobility arrangements should be structured to benefit from EC support (see page 187). George Marx and Carlos Ferreira, in summarizing opportunities for the new education group, gave a comprehensive overview of the rôle of several organizations (GIREP, IUPAP, UNESCO, International Council of Associations for Science Education, Academica Europea) in promoting physics teaching in schools. Most collaborate in organizing conferences for physics teachers so the Society will have to work hard to develop its own activities.

Finally, Derek Jefferies, who chairs the Working Group on Professional Qualifications, reported on progress in defining how a Register of European Physicists could be set up under the Society's auspices (someone entered on the Register would be a European Physicist - Eur Phys). The Executive Com-

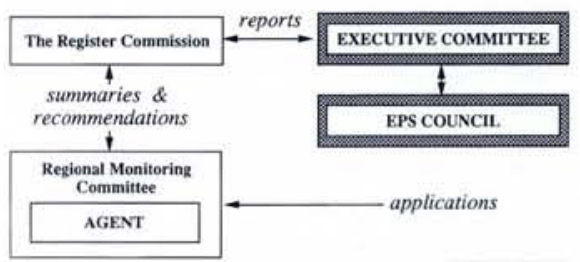

The proposed professional qualifications scheme. It is envisaged that there will be several Regional Monitoring Committees (RMC's) made up of delegates from national physical societies and of other bodies representing physicists. Individuals apply to the $R M C$ 's which make recommendations to the Register Commission responsible for standards and maintaining the Register of European Physicists. RMC's may appoint agents, e.g., national societies, to do their work. 
mittee will discuss proposals in November prior to their submission to Council next March, and if all goes well, launching of the scheme in late-1994. The scheme as it is formulated has the great advantage that it is in principle open to all European physicists at the very beginning without jeopardizing standards. National societies and other bodies will be invited to participate so it may take time to develop a network covering the whole of Europe. Pressure is building up from several quarters, so a start must be made based on a phased implementation.

\section{Seeking New Members}

Members speaking from the floor mainly commented on obvious problems or made constructive suggestions. The low participation by young people at EPS-9 preoccupied many. J. Mlynek, who chairs the Quantum Electronics and Optics Division, favoured combining the general conference with a Division conference. H. Schopper (Geneva) endorsed this idea since the formula of having a week-long technical conference with many parallel sessions overlapping with a one-day general conference works extremely well in Germany. The President remarked that the format of the General Conference was not tailored for students but for those settled in their work, so changes may be needed. They could be far reaching since it is necessary to consider moving from a "Society governed by research to one that is governed by society's issues". But more modest possibilities also exist for attracting younger participants. In particular, not enough is done to seek out young new talent capable of presenting top-class work ( $\mathrm{J}$. Bohr, Copenhagen).

Young scientists tend to focus on their immediate professional problems so they are naturally drawn to Division events which have no fundamental difficulty in attracting younger participants. But there could be improvements involving the organization of job markets (J. Mlynek) - mentioned earlier by the President - and the scheduling of parallel sessions. Such changes are crucial because the Divisions remain the most important avenue for attracting young people into the Society (D. Sette, Rome). As it is the Divisions' natural rôle to look after young scientists (R.A. Salmeron, Palaiseau) additional inducements should be developed while ensuring that young people are treated as full participants (e.g., they receive the proceedings). But one should not overdramatise the situation (R.A. Ricci, Legnaro) because even national general conferences seldom have more than $30 \%$ of participants who are students. The question is essentially cultural and the place to start acting is in schools.

There were a few remarks concerning membership. D. Sette felt that the Associate Members should be represented at the General Meeting. Indeed, G. Tibell (Uppsala) wondered why the meeting was restricted to ordinary members as the distinction between national society and EPS members is unclear. The Executive Committee has thought long and hard about ways to enhance the involvement of national society members and to make them more aware of the Society's work. The outcome will be a proposal to Council next March, the basis of which was strongly endorsed the day before by national society Presidents (see p. 184).

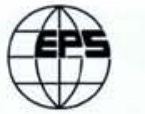

\section{Europhysics Notes}

\section{- Research Council Mission Clarified}

A report by the UK's minister of science published in May signalled major changes in the country's government-supported research councils with the creation of two new councils (Engineering and Physical Sciences Research Council - EPSRC - and Particle Physics and Astronomy Research Council PPARC) to replace the Science and Engineering Research Council (SERC) next April. The SERC Chairman stated that the SERC was disappointed that the number of Councils had been increased, that changes had been concentrated in part of the system, and that there was no indication of increased resources to help meet new challenges, especially in applied research. But, in general, the SERC supported the moves as the new structure will continue "... to develop capabilities in strategic research related to social and industrial needs."

A Boundary Study recommended in July that all physics (including nuclear structure physics) other than particle physics, astronomy and astrophysics, and solar system science should be allocated to EPSRC. The study also partially adopted SERC's suggestion to have the SERC's two large laboratories (Rutherford Appleton and Daresbury) under one Council by recommending placing them, in the long term, under common management by the Office of Public Service and Science to form a new institution working for all the Councils and able to sell services. In the short term, the two labs would remain EPSRC's responsibility. EPSRC should also take over the management of supercomputing from the SERC while the Advisory Board for the Research Councils (ABRC), which interfaces with all the Councils, studies future siting. (The ABRC supervised the first stage of a pioneering, and highly successful, programme in high-performance computing that led to the installation of a Cray Y-MP machine at Daresbury in 1992. Some 5-6 M£ is now

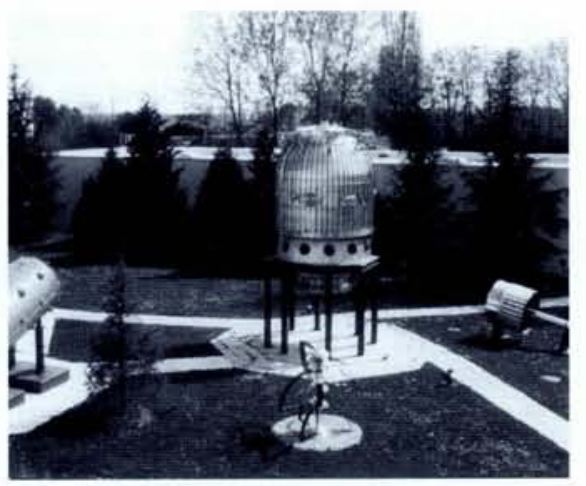

available for a second stage). PPARC will be responsible for CERN and ESA subscriptions and EPSRC for the ESRF and the ILL.

Nuclear physics initially found itself in an ambiguous position. In a survey by the SERC's Nuclear Physics Committee, the UK community regarded itself on scientific grounds as carrying out fundamental research with strong links to particle physics so it perhaps belonged in PPARC. But in the aftermath of the closure of Daresbury's Nuclear Structure Facility last year (which many felt was unnecessary and unjustified), and in view of the community having clearly identified radioactive ion beams (RIB's) as the top priority for the future, G.C. Morrison, the committee's chairman, sent a letter recommending a transfer to EPSRC "on political and managerial grounds". Central to the UK commitment is the Rutherford's $1.6 \mathrm{ME}$ RIB test-bed, endorsed by NuPECC in a recent report [EN 23 (1993) 80], which aims to demonstrate that powerful RIB's can be produced at a high-current accelerator (ISIS) for the first stage of a future European highintensity RIB facility.

It seems that the Boundary Study had never been in any doubt that nuclear physics would go to EPSRC as this had been the minister's intention all along. The nuclear community was concerned that the emphasis on basic research would be less in EPSRC than in PPARC because the words ".... but whose main objective is the improved understanding of the concepts and phenomena underlying physical phenomena and their consequences." were omitted from EPSRC's mission statement - something that prompted Alun Jones, the Chief Executive of The Institute of Physics, to call for EPSRC support for basic aspects of all the physical sciences. The extent to which this happens remains to be seen. However, it is unlikely that the nuclear community will be alone in carrying out fundamental work, so while ensuring that scientific collaboration with PPARC remains effective, the nuclear physicists aim to develop links with other areas of EPSRC by mainly building upon potential uses of the RIB facility.

\section{- Human Capital Last Chances}

The EC's Human Capital and Mobility programme has officially released the results of the second selection rounds for Large Installations, Institutes hosting fellows, Networks, and Euroconferences. The "Individual fellowships"activity has completed the fourth selection (lists are not released). Many details could be obtained informally when the selections finished back in June before the lengthy written procedure took over to formalise the decisions. So the information may not be so "hot" for some. Postdocs and graduates interested in a fellowship at one of the institutions selected by the EC must contact

MICROCOSM at CERN (the building is partly hidden by trees) is possibly the leading permanent exhibition sited at a major European facility. Officially proposed in 1988, it had welcomed 100000 visitors up to its inauguration on 8 September. The floor plan hopefully illustrates how an imaginative glimpse of what particle physics is all about was created with help from local authorities, other laboratories and industry.

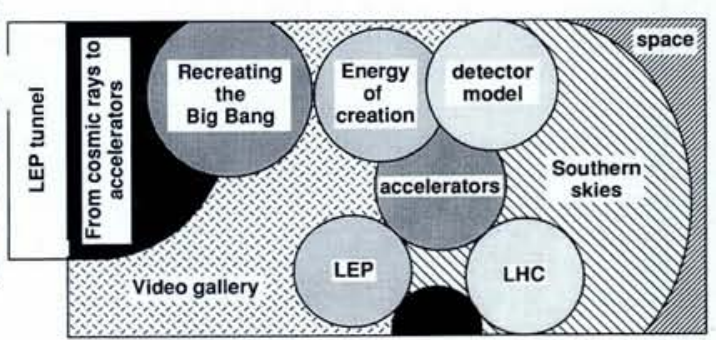

